\title{
Effect of Methanol Leaf Extract of Blighia Sapida on Mitochondrial Membrane Permeability Transition Pore Opening and Blood Glucose Levels in Normal and Streptozotocin-Induced Diabetic Rats
}

\author{
AO Olowofolahan*, EO Nwaokolo and 00 Olorunsogo \\ Department of Biochemistry, Laboratory for Membrane Biochemistry Research and Biotechnology, College of Medicine, \\ Nigeria
}

*Corresponding author: AO Olowofolahan, Department of Biochemistry, Faculty of Basic Medical Sciences, College of Medicine, Nigeria

\section{ARTICLE INFO}

Received: 豐 June 13, 2019

Published: 慧 June 21, 2019

Citation: AO Olowofolahan, EO Nwaokolo, 00 Olorunsogo. Effect of Methanol Leaf Extract of Blighia Sapida on Mitochondrial Membrane Permeability Transition Pore Opening and Blood Glucose Levels in Normal and Streptozotocin-Induced Diabetic Rats. Biomed J Sci \& Tech Res 19(1)-2019. BJSTR. MS.ID.003242.

Keywords: Mitochondrial membrane permeability transition pore; Blighia sapida; Cytochrome c; Apoptosis; Diabetes

\begin{abstract}
Blighia sapida (BS) is a medicinal plant used folklorically in the treatment of diabetes, but it is not known whether it could inhibit mitochondrial-mediated apoptosis and thus mitigate the excessive tissue wastage that is a hallmark of diabetes. This study therefore intended to evaluate antihyperglycemic and inhibitory effect of methanol leave extract of Blighia sapida (MEBS) on mitochondrial permeability transition (MPT) pore opening in normal and streptozotocin (STZ)-induced diabetic rat. Diabetes was induced with a single intraperitoneal administration of $60 \mathrm{mg} / \mathrm{kg}$ streptozotocin (STZ). Forty-five male (Wistar strain) rats were used in this study. The first set of animals (25 rats) were equally divided into five groups as follows; control, 50, 100, 200 and $400 \mathrm{MEBS} \mathrm{mg} / \mathrm{kg}$. The second set (20 rats) was also divided in to four groups as follows; control, MEBS (100 $\mathrm{mg} / \mathrm{kg})$, STZ $(60 \mathrm{mg} / \mathrm{kg})$, STZ+MEBS and STZ+Glibenclamide $(5 \mathrm{mg} / \mathrm{kg})$. The treatment was by oral administration for 28 days.

The results show that varying doses $(50,100$ and $200 \mathrm{mg} / \mathrm{kg}$ ) of MEBS did not induce MPT pore opening, However, in the streptozotocin-induced diabetic untreated rats, there was opening of the MPT pore which was significantly reversed by co-administration with MEBS. MEBS also significantly reversed the STZ-induced ATPase activity, lowered the elevated blood glucose level, mitigated lipid peroxidation, inhibited cytochrome c release and restored hepatic and pancreatic damage in the diabetic untreated rats. These findings suggest that Blighia sapida contains bioactive agents that have the potential to inhibit mitochondrial-mediated apoptosis and protect against streptozotocin-induced diabetes in rats.
\end{abstract}

\section{Introduction}

Diabetes mellitus is a chronic endocrine disorder, characterized by hyperglycemia resulting from absolute or relative insulin deficiency. It is a condition characterized by an elevation of the blood glucose level. Insulin, a hormone produced by the pancreas, controls the blood glucose level by regulating the production and storage of glucose. The etiopathogenetic categories of diabetes mellitus are type 1 diabetes mellitus and type 2 diabetes mellitus. In type 1 diabetes, the $\beta$ cells of pancreas produce inadequate amounts of insulin due to tissue wastage (autoimmune $\beta$-cell destruction) as a consequence of excessive apoptosis [1]. Apoptosis in beta cells is orchestrated by environmental factors and genetically susceptible factors [2]. Apoptosis is a strictly regulated (programmed) device responsible for the ordered removal of superfluous, aged or damaged cells [3]. Inappropriate apoptosis (either too little or too much) is a feature in many human conditions including neurodegenerative diseases, ischemic damage, autoimmune disorders and many types of cancer. 
Apoptosis in beta cells of the pancreas is a feature of type 1 diabetes. Apartfrom ATPgeneration, mitochondria have a prominent role in apoptosis initiation. The intrinsic or mitochondrial pathway of apoptosis is initiated by DNA damage and endoplasmic reticulum stress, which leads to permeabilization of the mitochondria outer membrane [4]. Mitochondrial permeability transition (MPT) pore opening disrupts the proton gradient of the inter membrane space configured by the electron transport chain of the inner mitochondria membrane, thus, uncoupling oxidative phosphorylation, rupture of the outer mitochondrial membrane, release of apoptogenic proteins such as cytochrome c, apoptosis inducing factor (AIF), endonuclease $G$ and small mitochondrial dependent activator of caspase (SMAC) [5,6]. The release of cytochrome $\mathrm{c}$ into the cytosol triggers caspase activation and ultimately apoptosis [7]. Studies have shown that there is a link between mitochondrial permeability transition (MPT) pore opening and diabetes [8].

Diabetes-induced mitochondrial dysfunction subsequently causes increase in free radical production, impaired antioxidant capabilities and dysregulation of mitochondrial permeability transition pore (MPT) opening which are related to the onset, progression and pathological consequences of diabetes $[9,10]$. It is clear that the MPT pore plays an important role in modulation of intrinsic pathway of apoptosis and therefore serves as a pharmacological target to the development of drugs that target the components of the MPT pore [11]. Research has shown that certain bioactive agents present in medicinal plants elicit their chemoprotective and therapeutic effects through the induction or inhibition of the opening of the pore [12]. Blighia sapida (BS) is a medicinal plant used folklorically in the treatment of diabetes, but it is not known whether it could inhibit mitochondrial-mediated apoptosis and thus mitigate the excessive tissue wastage that is a hallmark of diabetes. This study was therefore designed to investigate the effects of methanol leaf extract of Blighia sapida (MEBS) on mitochondrial permeability transition (MPT) pore opening, ATPase activity and lipid peroxidation in normal and streptozotocin (STZ)-induced diabetic rat.

\section{Materials and Methods}

\section{Chemicals and Reagents}

Mannitol, sucrose, N-2-Hydroxy-ethyl-pipearizine- $\quad \mathrm{N}-2$ ethanesulfonic acid (HEPES), rotenone, spermine, Folin-Ciocalteau reagent, streptozotocin, Bovine Serum Albumin (BSA), and all other reagents were purchased from Sigma-Aldrich Chemical Co. (St. Louis, MO, USA) and were of the highest purity grade available.

\section{Plant Material}

The leaves of Blighia sapida were obtained from a local farmland in Ibadan, Oyo State, Nigeria. Botanical identification and authentication were done at the Department of Botany, Faculty of Science, University of Ibadan, Ibadan, Nigeria. The fresh plant was separated from extraneous materials and washed. The leaves were air dried for about two weeks and then blended to powder.

\section{Preparation of Extract}

The powdered leaves were then soaked in Methanol for 72 hours. The filtrate obtained was concentrated using a Vacuum rotary evaporator (N-100, Eyla, Tokyo, Japan) and was later concentrated to dryness to yield methanol extract of Blighia sapida (MEBS) using a water bath at $37 \mathrm{oC}$ and the residues was transferred to a bottle and stored in a refrigerator until use.

\section{Experimental Animals}

Male Wistar strain albino rats weighing between 100-120g were purchased from the Preclinical Animal House of the College of medicine, University of Ibadan, Ibadan, Nigeria. All the animals were allowed to acclimatize for a period of two weeks in the Animal House of the Department of Biochemistry, University of Ibadan. The animals were placed under a $12 \mathrm{hr}$ light/dark cycle and fed commercial pelletized rat chow and water ad libitum throughout the experimental period. All experiments have been performed in accordance with the ethical standards laid down in the 1964 Declaration of Helsinki.

\section{Animals Groupings, Treatment and Sample Collections}

First Set: Thirty male Wistar rats were divided equally into five groups: Group A was the control group. Group B, C, D and E were treated with 50,100, 200 and $400 \mathrm{mg} / \mathrm{kg}$ MEBS respectively as a single dose daily by oral gavage for 28 days. One day after the final exposure, the animals were sacrificed. Blood was collected by cardiac puncture into plain sample bottles. Serum was prepared by centrifugation (3000rpm for $20 \mathrm{~min}$ ) and used for the analysis.

Second Set: Twenty male Wistar rats were used in this study

\section{a) Induction of Diabetes}

Diabetes was induced by a single intraperitoneal injection of streptozotocin (STZ) $(60 \mathrm{mg} / \mathrm{kg})$ to overnight fasted rats. Animals with fasting plasma glucose concentration (FPGC) $>300 \mathrm{mg} / \mathrm{dL}$ for 5 consecutive days were considered for this study using Accu-Chek glucometer (Roche diagnostics, Germany. The animals were divided and treated into various groups as follows:

Group 1: Non-Diabetic (control)

Group 2: Untreated Diabetic (STZ)

Group 3: Diabetic treated with MEBS (STZ+MEBS 100mg/kg)

Group 4: Diabetic treated with Glibenclamide (STZ+Glib)

\section{Isolation of Rat Liver Mitochondria}

Rat liver mitochondria were isolated essentially according to the method of Johnson and Lardy [13] and as modified by Olorunsogo et al. [14]. The animals were sacrificed by cervical dislocation and the livers excised and trimmed to wash excess tissue. The livers were then weighed, washed with homogenising buffer (210mM Mannitol, 70mM Sucrose, 5mM HEPES-KOH, pH 7.4 and $1 \mathrm{mM}$ EGTA), and homogenised as a $10 \%$ suspension in ice -cold 
buffer using a Porter Elvehjem glass homogenizer. The resulting homogenate was centrifuged in an MSE refrigerated centrifuge at $2300 \mathrm{rpm}$ for 5 mins to remove the nuclear debris. This was done twice, and the supernatant obtained was centrifuged at 13,000 rpm for 10 mins to obtain the mitochondrial pellet. The supernatant was discarded while the pellet was washed twice with the washing buffer (210mMMannitol, 70mM sucrose, 5mM HEPES-KOH, pH 7.4, $0.5 \% \mathrm{BSA}$ ) at $12,000 \mathrm{rpm}$ for $10 \mathrm{mins}$. The mitochondria obtained were immediately resuspended in an appropriate volume of MSH buffer (210mM Mannitol,70mM sucrose, 5mM HEPES-KOH, pH 7.4), and immediately dispensed into Eppendorf tubes and kept on ice.

\section{Mitochondrial Swelling Assay}

Mitochondrial membrane permeability transition was monitored by measuring changes in absorbance of mitochondrial suspension in the presence or absence of calcium (the triggering agent) in aT70 UV/visible spectrophotometer essentially according to the method of Lapidus and Sokolove [15] Mitochondria (0.4mg protein $/ \mathrm{ml}$ ) were preincubated in the presence of $0.8 \mu \mathrm{M}$ rotenone in a medium containing $210 \mathrm{mM}$ mannitol, $70 \mathrm{mM}$ sucrose and $5 \mathrm{mM}$ HEPES-KOH ( $\mathrm{pH} \mathrm{7.4)} \mathrm{for} 3$ mins at $27^{\circ} \mathrm{C}$ prior to the addition of $120 \mu \mathrm{M} \mathrm{CaCl}_{2}$. Thirty seconds later, $5 \mathrm{mM}$ succinate was added and mitochondrial permeability transition quantified at $540 \mathrm{~nm}$ for $12 \mathrm{mins}$ at 30 secs interval. To test the intactness of the mitochondria, $4 \mathrm{mM}$ spermine was added immediately following the addition of rotenone and just before the addition of mitochondrial fraction.

\section{Determination of Mitochondrial Protein}

Mitochondrial protein concentration was determined according to the method of Lowry et al. [16] using bovine serum albumin as standard.

\section{Assesment of Mitochondrial FOF1 Atpase Activity}

$\mathrm{F}_{0} \mathrm{~F}_{1}$ Adenosine triphosphatase which was determined by the method of Olorunsogo and Malomo [17]. Each reaction mixture contained $65 \mathrm{mM}$ Tris- $\mathrm{HCl}$ buffer $\mathrm{pH} 7.4,0.5 \mathrm{mM} \mathrm{KCl}, 1 \mathrm{mM}$ ATP and $25 \mathrm{mM}$ sucrose. The reaction mixture was made up to a total volume of $2 \mathrm{~mL}$ with distilled water. The reaction was started by the addition of mitochondrial suspension and was allowed to proceed for 30 mins at $27^{\circ} \mathrm{C}$. The reaction was stopped by the addition of 1 $\mathrm{ml}$ of a $10 \%$ solution of sodium dodecyl sulphate. The zero-time tube was prepared by adding the solution of ATP to the reaction vessel following the addition of sodium dodecyl sulphate. 2,4 Dinitrophenol (2,4 DNP) was used as a standard uncoupling agent.

\section{Estimation of Inorganic Phosphate Released}

The concentration of inorganic phosphate released following the hydrolysis of ATP was determined according to the method described by Bassir [18] and as modified by Olorunsogo and Bababunmi [14]. 300 $\mu$ l of each solution was dispensed into fresh test tubes, followed by the addition of $300 \mu$ l of distilled water to each of the test tube. To this was added $1 \mathrm{ml}$ of $5 \%$ ammonium molybdate and $1 \mathrm{ml}$ of $9 \%$ freshly prepared solution of ascorbic acid. The tube was well mixed and allowed to stand for 20 minutes. The absorbance was read at $680 \mathrm{~nm}$.A water blank was used to set the spectrophotometer at zero.

\section{Lipid Peroxidation}

The lipid peroxidation was determined by the method of Varshney and Kale [19]. $0.4 \mathrm{ml}$ of the test sample, $1.6 \mathrm{ml}$ of Tris$\mathrm{KCl}$ buffer and $0.5 \mathrm{ml}$ of $30 \%$ TCA were dispensed into a test tube. This was followed by the addition of $0.5 \mathrm{ml}$ of $0.75 \%$ TBA and the mixture placed in a water bath set at $80 \mathrm{oC}$ for 45 minutes. It was cooled, centrifuged at $3000 \mathrm{rpm}$ for $10 \mathrm{~min}$. and absorbance of the supernatant was measured at $532 \mathrm{~nm}$.

\section{Determination of Cytochrome c Release}

The quantitative determination of cytochrome c released from isolated mitochondria was performed by measuring the Soret $(\gamma)$ peak for cytochrome $c$ at $414 \mathrm{~nm}\left(\varepsilon=100 \mathrm{mM}^{-1} \mathrm{~cm}^{-1}\right)$, according to method of Appaix et al. [20]. Mitochondria (1mg protein $/ \mathrm{ml}$ ) were preincubated in the presence of $0.8 \mu \mathrm{M}$ rotenone in a medium containing $210 \mathrm{mM}$ mannitol, $70 \mathrm{mM}$ sucrose and $5 \mathrm{mM}$ HEPES$\mathrm{KOH}\left(\mathrm{pH}\right.$ 7.4) for $30 \mathrm{mins}$ at $27^{\circ} \mathrm{C}$ in the presence of different concentrations of the fractions, using $24 \mathrm{mM}$ calcium as the standard (TA). After the incubation, the mixture was centrifuged at $15,000 \mathrm{rpm}$ for $10 \mathrm{mins}$. The optical density of the supernatant was measured at $414 \mathrm{~nm}$ which is the soret $(\gamma)$ peak for cytochrome c.

\section{Preparation of Immunohistochemistry Samples}

Briefly, liver sections were immersed in $10 \%$ phosphate buffer formalin, dehydrated in graded alcohol and embedded in paraffin. Fine sections were obtained and mounted on glass slides. The method used in this study is Avidin Biotin Complex (ABC) method also referred to the Avidin biotin Imuunoperoxidase method. The antibody dilution factor used were 1:100 dilution for all the antibody markers.

\section{Immunohistochemical Assays}

Primary antibodies used in this study was cytochrome c, (Elabscience product). Immunohistochemical staining was performed according to the manufacturer instructions.

\section{Tissue Preparation for Histopathology}

Liver was used for histopathology. They were quickly removed and trimmed and were placed in $10 \%$ formalin for about five days for proper fixation, dehydrated by ascending grades of isopropyl alcohol for an hour. The dehydrated organs were cleared in xylene and transferred into two changes of liquid paraffin wax. The tissue sections were stained in Ehrlich's hematoxylin for eight minutes, washed in tap water and dipped in acid alcohol to remove excess stain. These were counter stained in $10 \%$ aqueous eosin, incubated and mounted for photomicrography. The Histological pictures were taken with a Digital Microscope, VJ-2005 DN MODEL BIOMICROSCOPE ${ }^{\circledR}$. 


\section{Statistical Analysis of Data}

Statistical analysis was performed using one-way analysis of variance (ANOVA). Level of significance was set at $p<0.05$ and all the results were expressed as mean \pm standard deviation (SD).

\section{Results}

As shown in Figure 1, there was no change in volume of mitochondrial respiring on succinate over a period of twelve minutes. On addition of calcium, which is a standard triggering agent, there was a significant induction of pore opening which was almost completely reversed on addition of spermine, a standard inhibitor. This shows that the mitochondria used in this study were intact and suitable for use. The Figure 2 shows the effect of varying concentrations of MEBS (10 to $90 \mu \mathrm{g} / \mathrm{ml}$ ) on MPT pore opening. The results show that there was no induction of MPT pore opening at all the concentrations tested in the absence of calcium. Furthermore, calcium-induced pore opening was reversed by MEBS at all the concentrations used in this study as depicted in Figure 3.

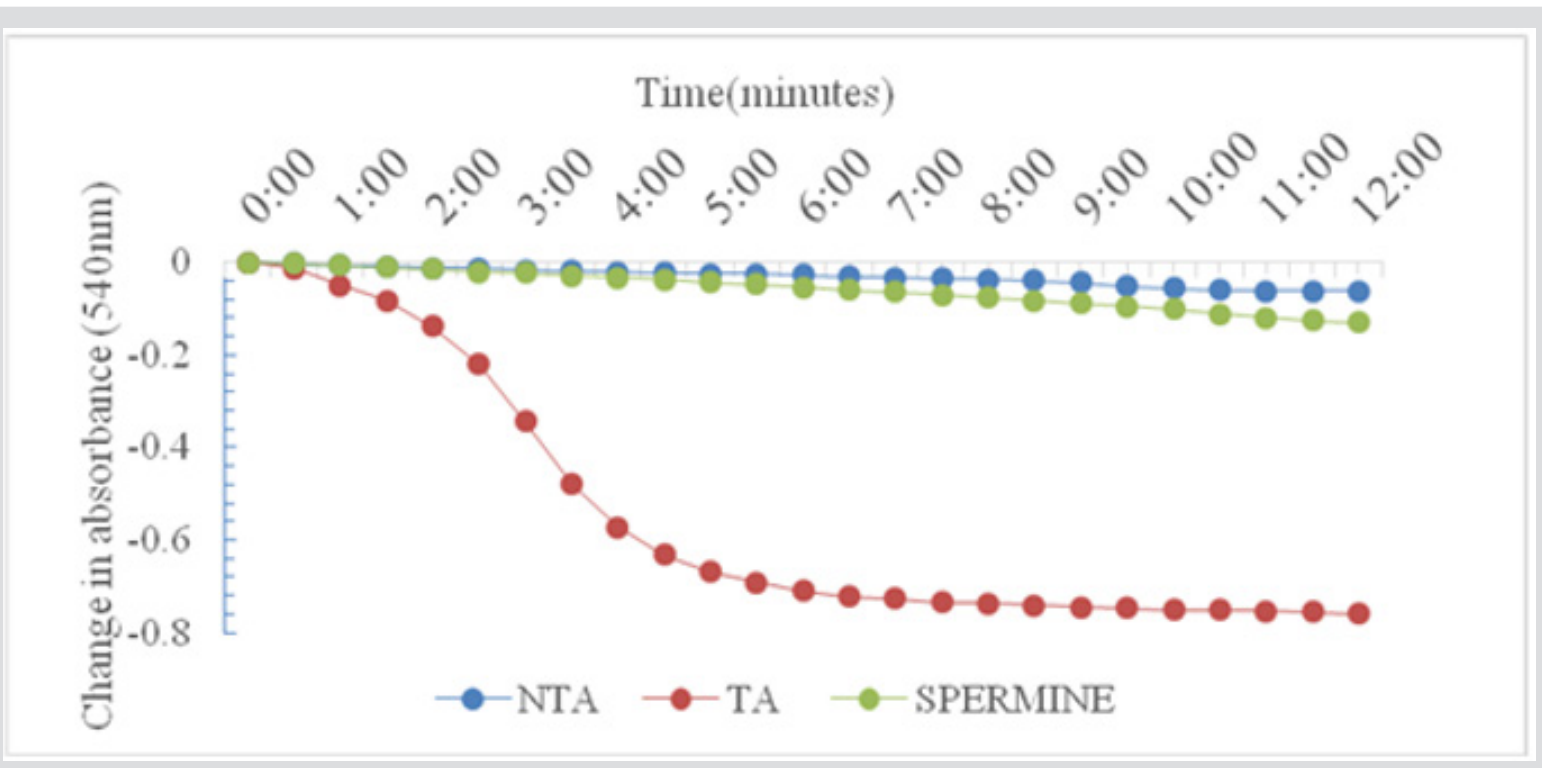

NTA: No triggering agent TA: Triggering agent

Figure 1: Calcium-induced mitochondrial membrane permeability transition pore opening in normal rat liver mitochondria and its reversal by Spermine.

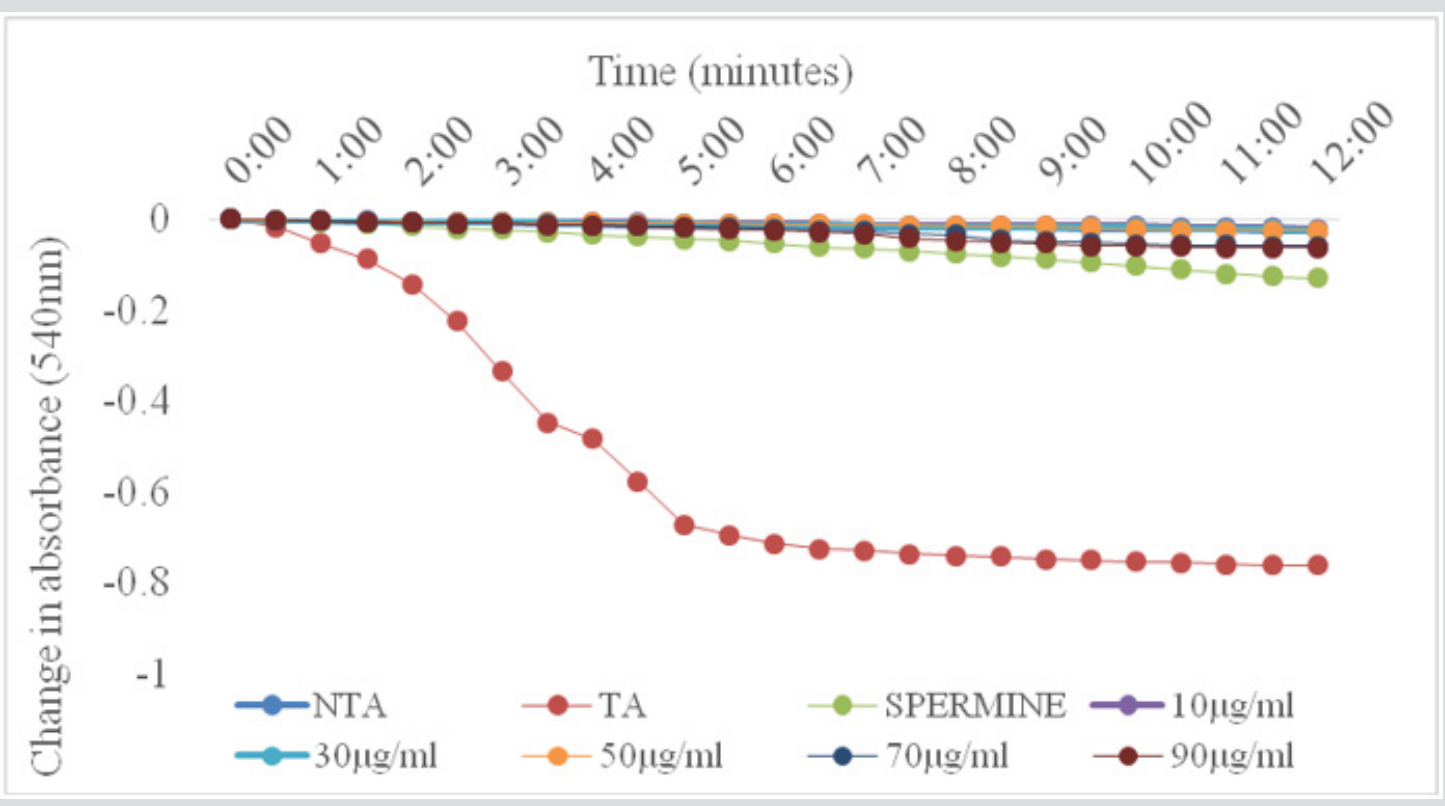

Figure 2: Effect of varying concentrations of MEBS on the MPT pore in the absence of $\mathrm{Ca}^{2+}$. 


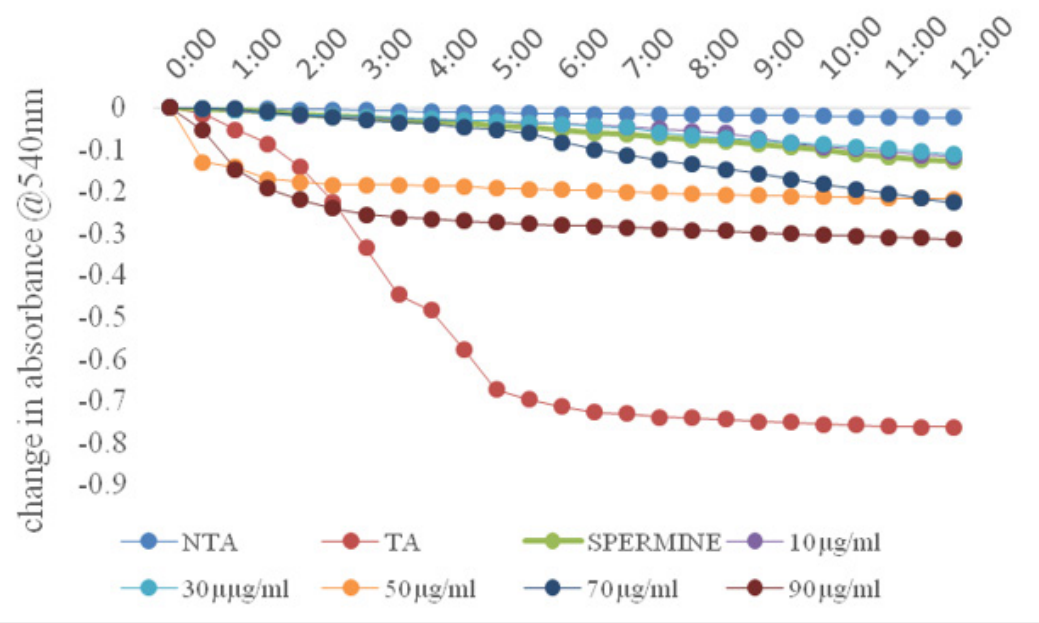

Figure 3: Effect of varying concentrations of MEBS on the MPT pore in the presence of $\mathrm{Ca}^{2+}$.

Figures $4 \& 5$ also show similar pattern of results in that varying concentrations of MEBS neither cause any release of cytochrome c nor enhancement of ATPase activity, respectively, at all the concentrations tested. Interestingly, at 50, 70 and $90 \mu \mathrm{g} / \mathrm{ml}$, there was significant inhibition of cytochrome $c$ release and at 70 and $90 \mu \mathrm{g} / \mathrm{ml}$, the enhancement of ATPase activity was significantly reduced when compared with the control as shown by Figures 4 $\& 5$, respectively. Table 1 shows the blood glucose level $(\mathrm{mg} / \mathrm{dl})$ in normal and streptozotocin-induced diabetic rats when treated with

Table 1: Effect of methanol leaf extract of Blighia sapida on blood glucose level (mg/d).

\begin{tabular}{|c|c|c|c|c|}
\hline Groups & $\begin{array}{c}\text { Initial Blood glucose } \\
\text { (mg/d) }\end{array}$ & $\begin{array}{c}\text { Blood Glucose after STZ } \\
\text { injection (mg/d) }\end{array}$ & $\begin{array}{c}\text { Blood glucose after 2 } \\
\text { weeks (mg/d) }\end{array}$ & $\begin{array}{c}\text { Blood glucose at sacrifice } \\
\text { (mg/dl) }\end{array}$ \\
\hline Non-Diabetic Control & $87.4 \pm 4.2$ & $91.8 \pm 6.2$ & $86.5 \pm 7.9$ & $82.6 \pm 4.4$ \\
\hline Diabetic Untreated (STZ only) & $87.3 \pm 7.4$ & $340.6 \pm 10.9$ & $379.8 \pm 11.2$ & $429.7 \pm 15.1$ \\
\hline $\begin{array}{c}\text { Diabetic treated with extract } \\
\text { (STZ+MEBS) }\end{array}$ & $81.6 \pm 9.1$ & $319.5 \pm 16.7$ & $271.1 \pm 15.3$ & $110.4 \pm 3.6$ \\
\hline $\begin{array}{c}\text { Diabetic treated with } \\
\text { Glibenclamide (STZ+Glib) }\end{array}$ & $90.7 \pm 6.8$ & $339.2 \pm 20.6$ & $265.8 \pm 18.4$ & $100.3 \pm 12.3$ \\
\hline
\end{tabular}

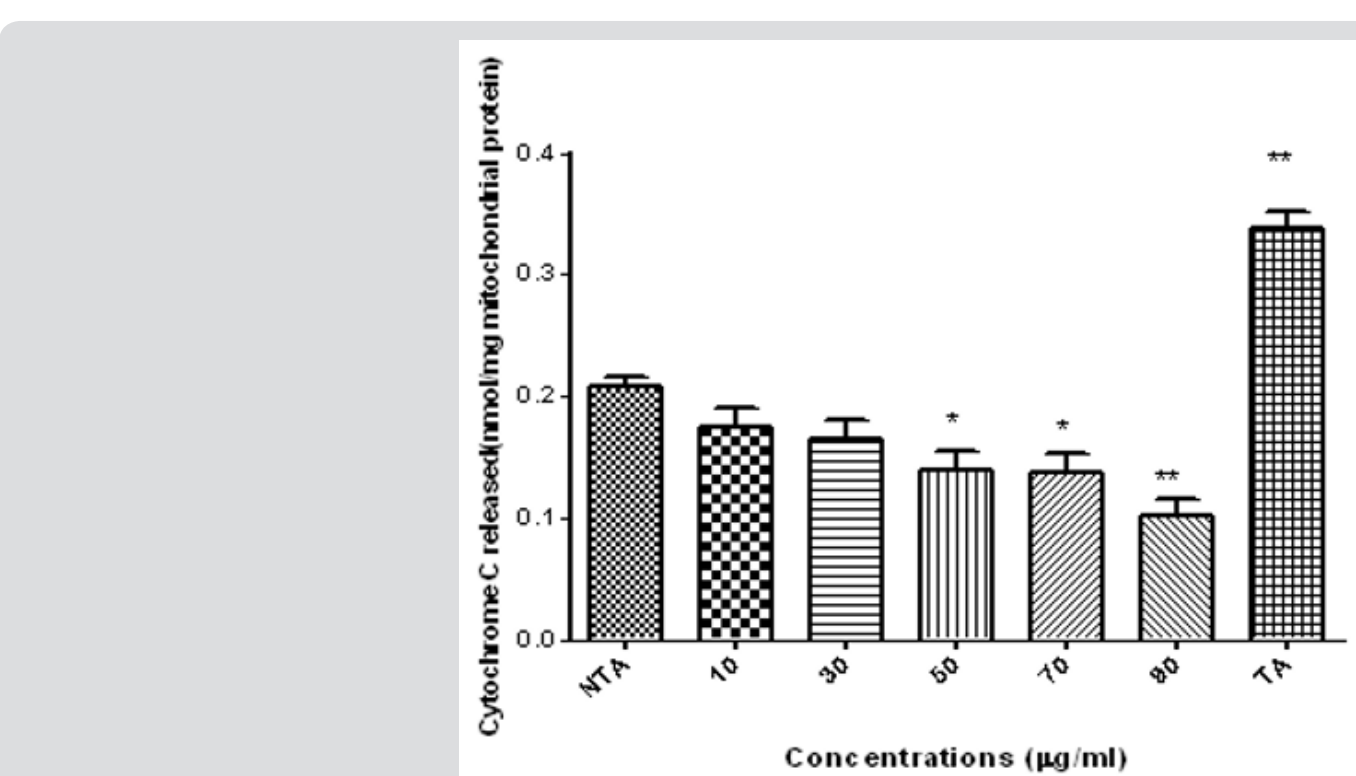

Figure 4: Effects of varying concentrations of MEBS on Cytochrome c release.
MEBS and standard drug, glibenclamide. There was no significant elevation of the blood glucose level of the non-diabetic control rats from the beginning to the end of the experiment. In the diabetic untreated group (STZ only), there was significant increase in the blood glucose level after 72 hours of STZ injection. The increase from $87.3 \pm 7.4$ to $340.6 \pm 10.9 \mathrm{mg} / \mathrm{dl}$ was recorded after 72 hours, $379.8 \pm 11.2 \mathrm{mg} / \mathrm{dl}$ was recorded after 2 weeks of STZ injection while $429.7 \pm 15.1 \mathrm{mg} / \mathrm{dl}$ was recorded at the point of sacrifice. 


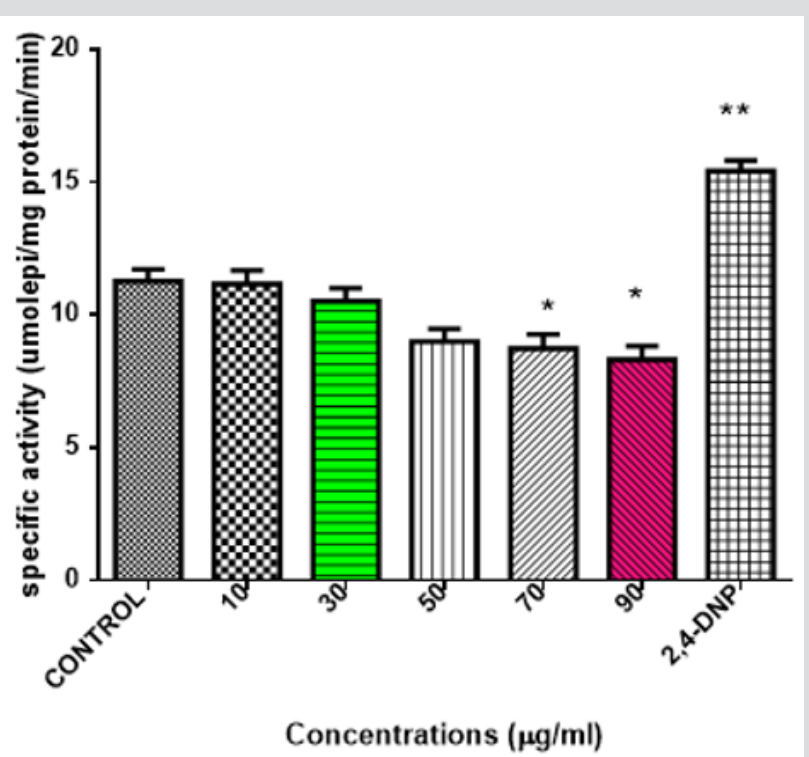

Figure 5: Effects of varying concentration of MEBS on mitochondrial ATPase activity.

In the diabetic group treated with extract, (STZ+MEBS), the blood glucose level after 72 hours post STZ injection was $319.5 \pm 16.7 \mathrm{mg} / \mathrm{dl}$. This level was remarkably decreased to $271.1 \pm 15.3 \mathrm{mg} / \mathrm{dl}$ after 2 weeks of treatment with MEBS and the decrease was more significant after 4 weeks as it was lowered to $110.4 \pm 3.6 \mathrm{mg} / \mathrm{dl}$. Similar pattern was recorded in the STZ group cotreated with glibenclamide. The glucose level $(339.2 \pm 20.6 \mathrm{mg} / \mathrm{dl})$, 72 hours post STZ injection was lowered to $265.8 \pm 18.4 \mathrm{mg} / \mathrm{dl}$ after 2 weeks of treatment and $107.3 \pm 12.3$ after 4 weeks. Figure 6 shows the effects of oral administration of MEBS on MPT pore opening in
STZ- induced diabetic rats after 28 days of treatment. Evidences emerging have linked mitochondrial pore opening with diabetes [8]. As shown from the graph, there was significant induction of pore opening (16.3 folds) in the diabetic untreated group (STZ only) when compared with the non-diabetic control. This induction of pore opening was significantly reversed in the diabetic group co-treated with MEBS (STZ+MEBS) to 2.1 folds compared with the non-diabetic control. The standard drug also shows significant reversal of pore opening to 5.5 folds relative to the non-diabetic control.

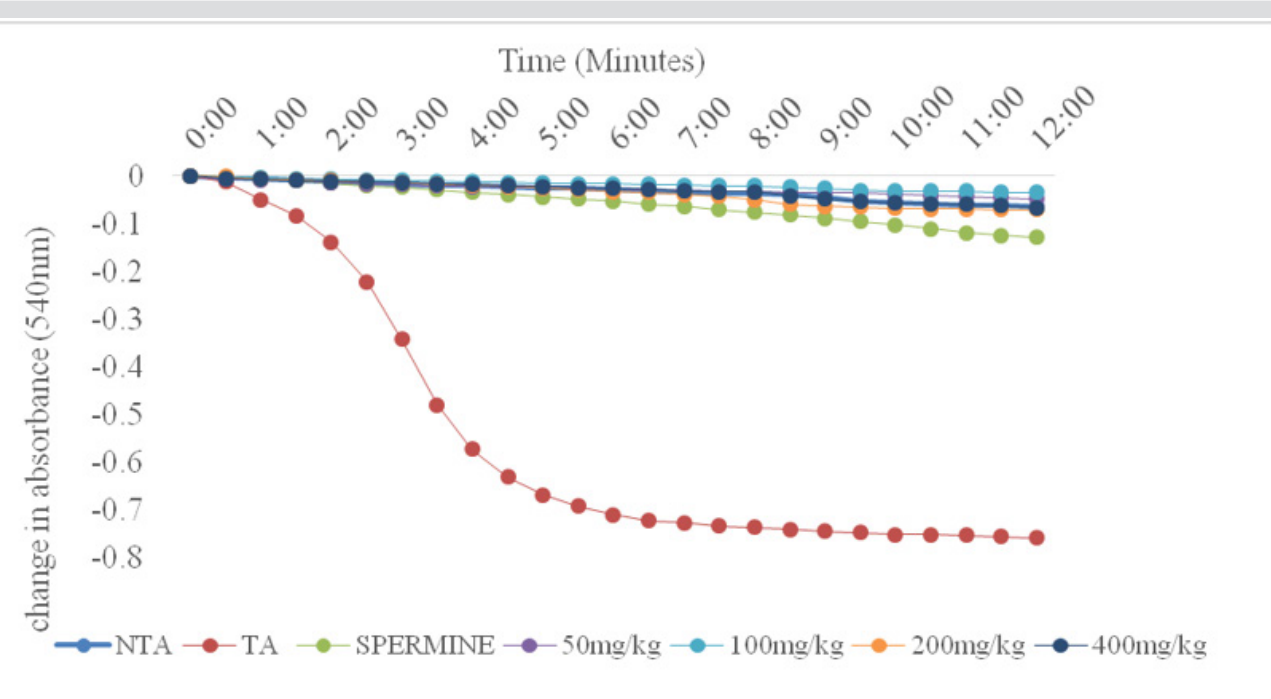

Figure 6: Effect of oral administration of MEBS on MPT pore opening in STZ-induced diabetic rats after 28 days of treatment.

The mitochondrial ATPase activity was significantly enhanced in the diabetic untreated group when compared with the nondiabetic control, however, this effect was significantly reversed in the diabetic group treated with MEBS and glibenclamide using 2,4, Dinitrophenol (2,4 DNP) as a standard uncoupler. There was no statistical difference between the non-diabetic control, diabetic treated with MEBS and diabetic treated with glibenclamide as depicted in Figure 7. The lipid peroxidation status in the diabetic untreated was significantly increased when compared with the non-diabetic control. This effect was also lowered in the diabetic group co-treated with MEBS and glibenclamide. There was no statistical difference between the non-diabetic control and the diabetic treated with MEBS and diabetic treated with glibenclamide (Figure 8). 


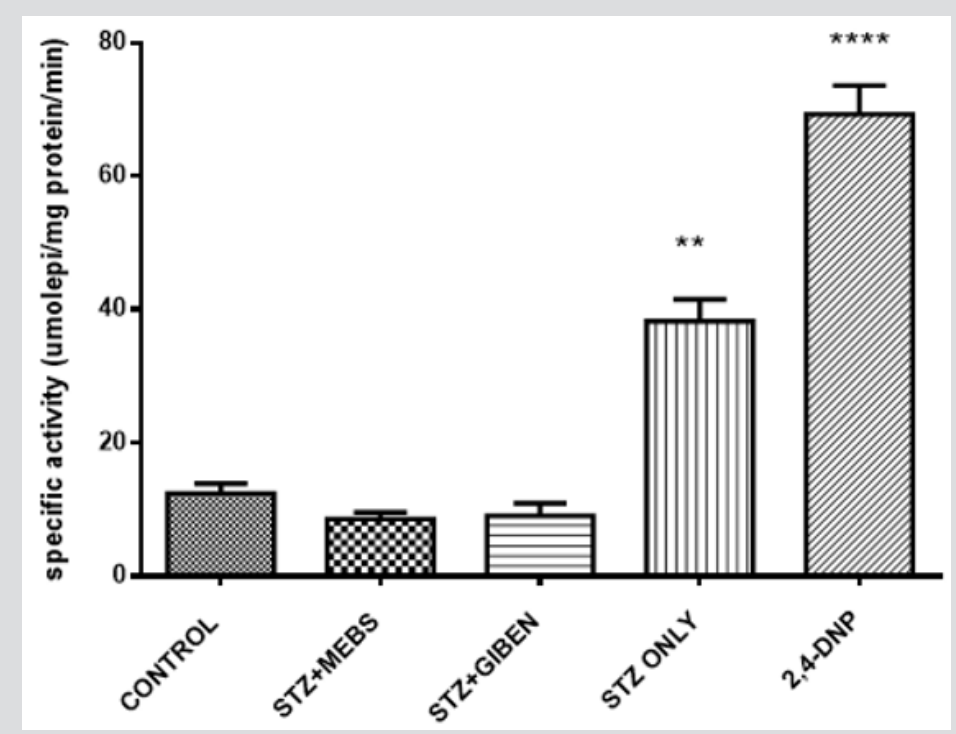

Abbreviations:

CONTROL: Normal Rats

STZ+MEBS: STZ -induced diabetic rats orally treated with MEBS $100 \mathrm{mg} / \mathrm{kg}$

STZ+Glib: STZ -induced diabetic rats orally treated with Glibb $5 \mathrm{mg} / \mathrm{kg}$

STZ ONLY: STZ -induced diabetes rats

Figure 7: Mitochondrial ATPase activity in the normal, treated and untreated diabetic rats.

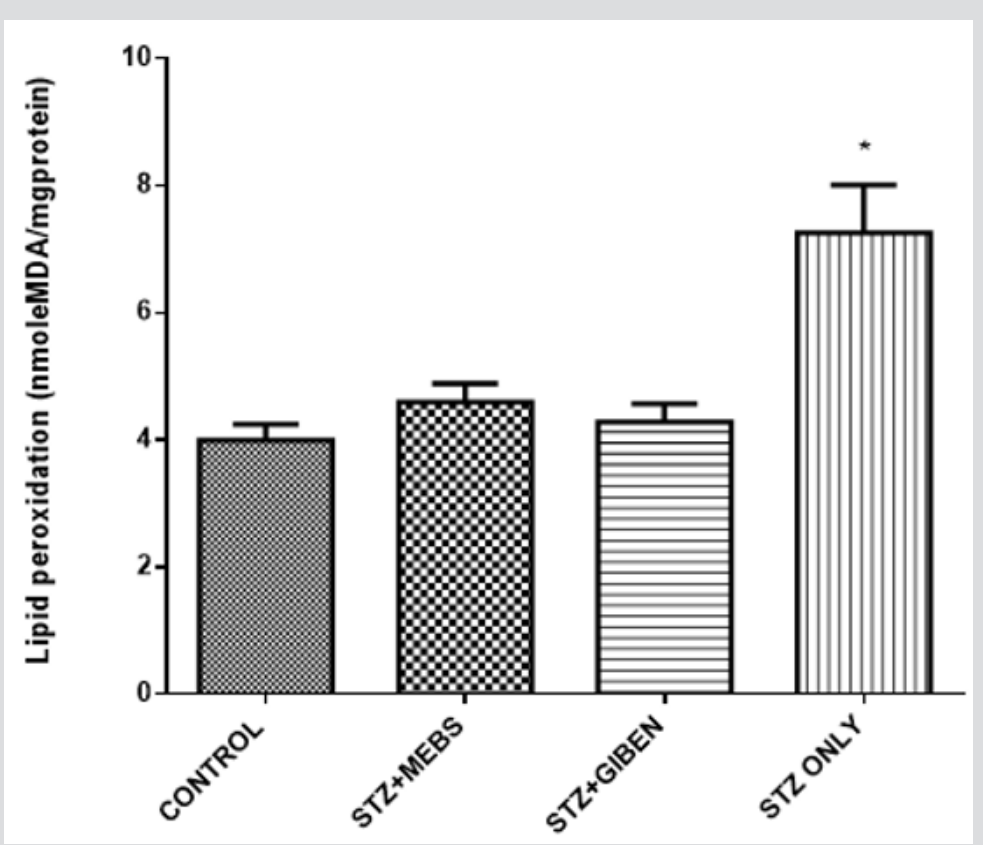

Figure 8: Lipid peroxidation status in the control, treated and untreated STZ-induced diabetic rats after 28 days.

The findings from the immunohistochemical analysis of cytochrome c revealed that the hepatocytes of non-diabetic control showed negative expression of cytochrome $c$ while the diabetic untreated (STZ only) showed a strong positive immunoexpression of cytochrome c. However, there was negative expression of cytochrome $\mathrm{c}$ in the groups co-administered with glibenclamide and MEBS, respectively as depicted in Figure 9. Also, the histological study showed gross lesion in the liver and pancreas of diabetic untreated rat. This was ameliorated by co-administration with MEBS. Similar result was obtained in the group co-administered with glibenclamide though there was congestion of vessel and sinusoid. 


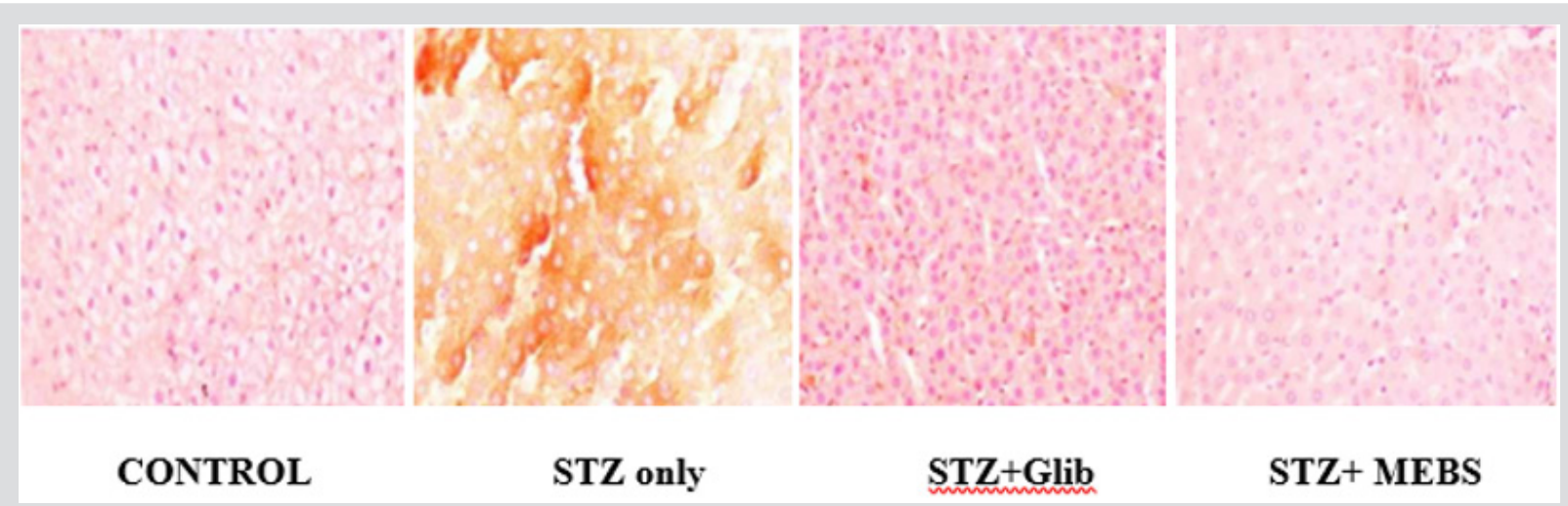

Figure 9: Immunohistochemical analysis of cytochrome c release in the liver of non-diabetic control, treated and untreated STZ-induced diabetic rats.

\section{Discussion}

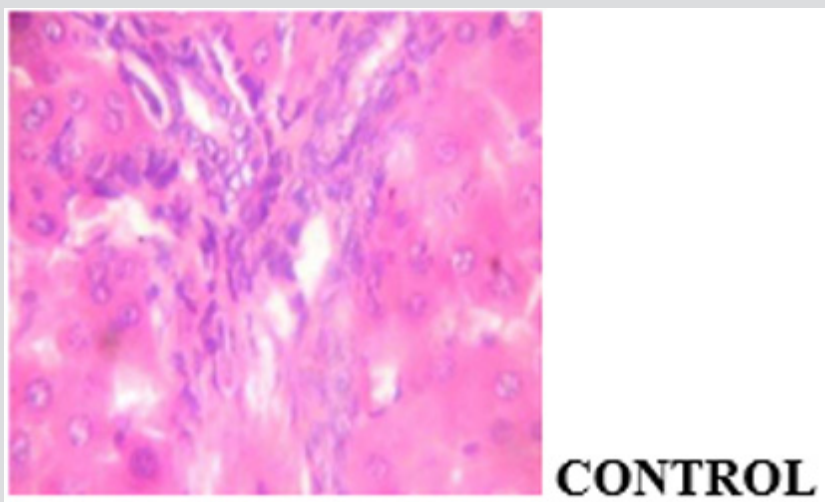

Figure 10a: Plates show no significant lesion.

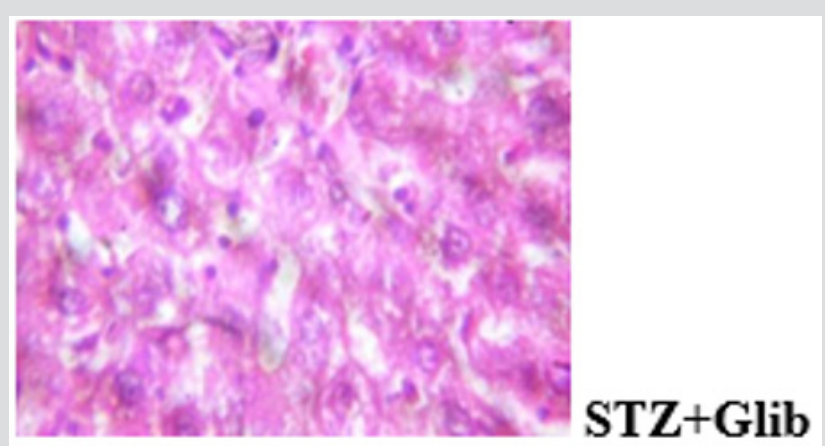

Figure 10b: Plates show disseminated congestion, multifocal area of thrombosis and disseminated periportal infiltration by inflammatory cells.

Hyperglycemia affects the different stages in apoptotic signaling by increasing oxidative and nitrosative stress and also activating the proapoptotic Bcl-2 family proteins and caspase cascade [21]. Understanding that decreased beta cell mass is an important factor in the pathogenesis of diabetes, protection of beta cells against excessive apoptosis could be a therapeutic target for diabetes. The mitochondrial-dependent pathway of apoptosis via mitochondrial permeability transition (MPT) pore opening was investigated in normal and streptozotocin-induced diabetic rat. In the in vitro experiment, the mitochondrial intactness was established as the exogenous calcium induce the opening of the membrane permeability transition (MPT) pore, while spermine a potent inhibitor significantly reversed the $\mathrm{Ca}^{2+}$-induced pore opening. This indicated that the membrane integrity of the liver mitochondria was not compromised, hence, the mitochondria were suitable for use. The methanol extract of Blighia sapida did not induce the opening of the MPT pore at all the concentrations used. Similarly, there was neither the release of cytochrome c nor enhancement of ATPase activity by MEBS at all the tested concentrations. In fact, at $90 \mu \mathrm{g} / \mathrm{ml}$, there was significant inhibition of cytochrome c release and ATPase activity. Photomicrograph showing the histological changes in the liver of non-diabetic control, diabetic treated and diabetic untreated rats (Figure 10a-10d).

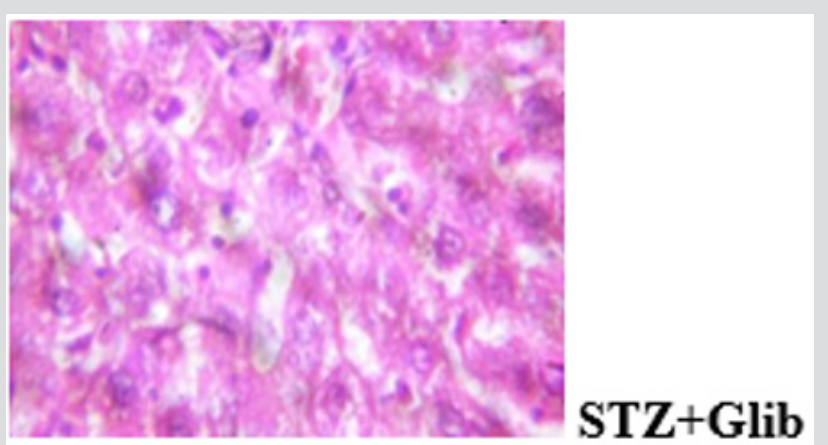

Figure 10c: Plates show disseminated congestion, moderate disseminated micro vesicular steatosis and very mild infiltration of zone 2 by inflammatory cells.

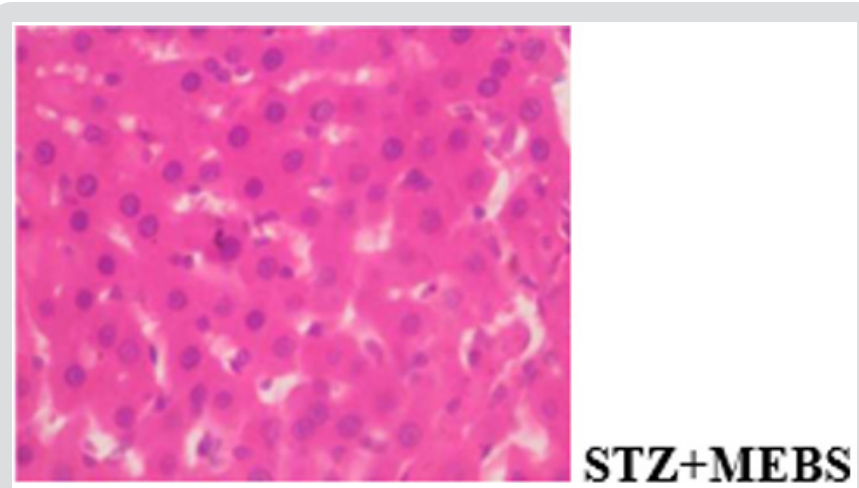

Figure 10d: Plates show mild disseminated periportal infiltration by inflammatory cells. 
The results of the oral administration of MEBS at all the dosage used also show no induction of pore opening. This is probably suggesting that MEBS contains phytochemicals that cannot induce MPT pore opening and thus cannot cause the release of cytochrome c. The inhibitory effect noticed at $90 \mu \mathrm{g} / \mathrm{ml}$, suggests that the phytochemicals present in the plant might be relevant in cases where apoptosis needs to be inhibited or reversed. Since there was no induction in vitro and in vivo, and rather, there was inhibition at the highest concentration used, this instigated our curiosity to investigate the effect of MEBS in a diseased condition associated with tissue wastage as a result of excess apoptosis. Diabetes mellitus type 1 is a diseased condition associated with tissue wastage as a result of destruction of the beta cells of the pancreas thereby causing hyperglycemia. This diseased condition was mimicked in rat model by single intraperitoneal injection of $60 \mathrm{mg} / \mathrm{kg}$ streptozotocin. The blood glucose level was monitored and those that were diabetic were grouped into the diabetic untreated (STZ only), diabetic but treated with MEBS (STZ+MEBS) and diabetic but treated with glibenclamide which a standard drug is (STZ+Glib). The results on the glucose level as indicated by Table 1 shows that MEBS has the potential to ameliorate the hyperglycemic effect in STZ-treated rats. Photomicrograph showing the histological changes in the pancreas of nondiabetic control, diabetic untreated and diabetic treated rats (Figure 11a-11d).

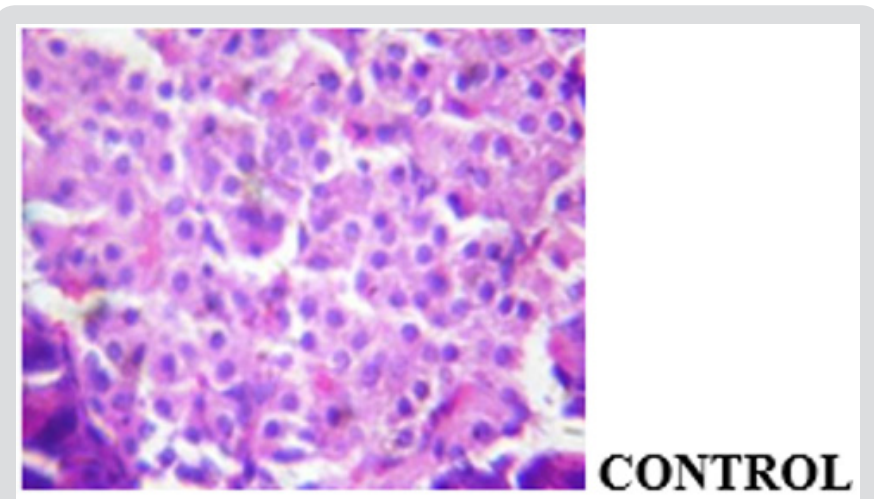

Figure 11a: The islet shows normal morphology.

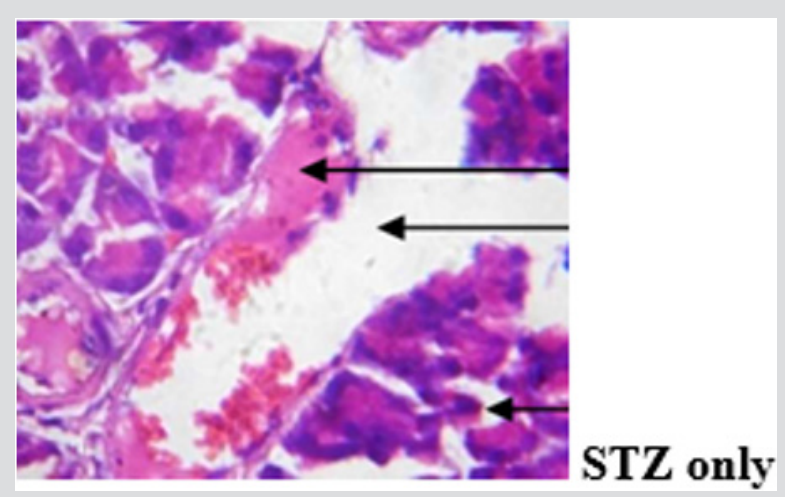

Figure 11b: Plates show marked disseminated congestion as well as thrombosis. The islets show vacuolation, desquamation and congestion, there is focal area of vacuolation of the exocrine acini while the ducts contain eosinophilic fluid.

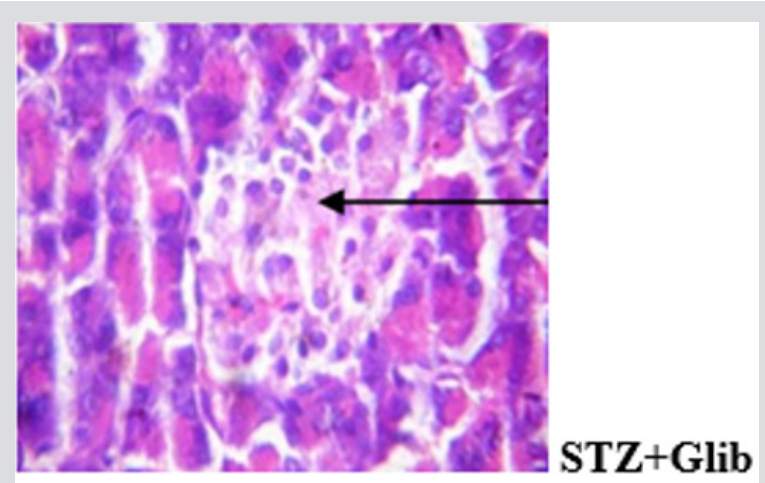

Figure 11c: Islets show mild desquamation and disseminated congestion.

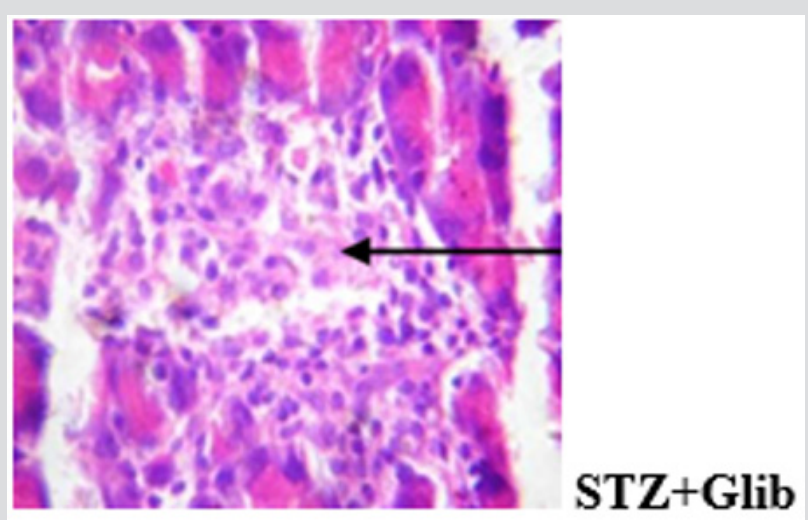

Figure 11d: Plates show disseminated congestion and focal area of very mild infiltration of the parenchyma. The islets show normal morphology.

The MEBS was able to reduce the blood glucose level from $319.5 \pm 16.7$ to $110.4 \pm 3.6 \mathrm{mg} / \mathrm{dl}$ after the 4 weeks of treatment. This is statistically significant when compared with the untreated group which has glucose level of $429.7 \pm 15.1 \mathrm{mg} / \mathrm{dl}$ at the end of 4 weeks. Similar pattern of result was recorded in the case of glibenclamidetreated diabetic rats. The drug reversed the hyperglycemia from $339.2 \pm 20.6$ to $107.3 \pm 12.3 \mathrm{mg} / \mathrm{dl}$. Since type 1 diabetes has been associated with excess apoptosis of the beta cells, the effect of MEBS was further investigated on MPT pore status of the STZinduced diabetic rats. From the results, it was discovered that there was induction of MPT pore opening in the STZ-induced diabetic rats which was significantly reversed in the group co-treated with MEBS. This suggests that MEBS contains phytochemicals that can reverse or inhibit mitochondrial-mediated apoptosis and thus be relevant in situations where apoptosis needs to be reversed in inhibited like type 1 diabetes.

The glibenclamide too significantly reversed the MPT pore opening. When there is MPT pore opening, cytochrome c is released, and mitochondrial ATPase activity is enhanced. As shown in Figure 7, there was enhanced ATPase activity in the STZ-induced diabetic rats. This occurred as a consequence of the MPT pore opening that featured in the STZ-induced diabetic rats. From the same Figure 7, there was reversal of the ATPase activity in the group co- 
treated with MEBS and glibenclamide respectively. This is because they reversed MPT pore opening and thus prevent the excessive apoptosis that could lead to tissue wastage which is a hallmark in type 1 diabetes. The results on the lipid status also show that the production of malondialdehyde in STZ-induced diabetic rat is very high when compared with the control, however, this was remarkably lowered in the group that receive co-administration with MEBS and glibenclamide respectively. This suggests that MEBS contains bioactive agents that might also be relevant in protecting against lipid peroxidation-induced damage or oxidative stress associated with diabetes.

The histological findings showed that MEBS contains phytochemicals that can protect against STZ-induced hepatocellular and pancreatic injury in rats as the gross lesion in the diabetic untreated rat was reversed in the group co-administered with MEBS. The result of the immunohistochemical analysis of cytochrome c showed that streptozotocin caused positive expression of cytochrome $\mathrm{c}$ while co-administration with MEBS showed negative expression. This shows that co-administration with MEBS prevented/inhibited the expression of cytochrome c. This result is in consonant with our in vitro result where MEBS did not cause any release of cytochrome c. This in vivo result on immunohistochemistry further confirms that MEBS does not cause the release of cytochrome c, it rather prevents the release. Blocking the release of cytochrome c prevents mitochondrial-mediated apoptosis.

In these findings, it can be concluded that streptozotocin induced hyperglycemia which was reversed by methanol extract of Blighia sapida (MEBS). Also, STZ induced MPT pore opening which was significantly reversed by MEBS. The cytochrome c which was positively expressed in diabetic untreated rats (STZ only) was downregulated in the group co-treated with MEBS. This shows MEBS to be an inhibitor of pore opening and thus inhibitor of mitochondrial-mediated apoptosis. It also shows that MEBS can reverse hyperglycemia which is characteristics of diabetes. Furthermore, the diabetic rat group treated with MEBS exhibited recovery from hepatic and pancreatic injuries. This could be due to the presence of antioxidants phytochemicals which might be present in the methanol extract. This study justifies the folkloric use of the plant in the treatment of diabetes. Though, the nature of substances responsible for the effects shown by MEBS are still unknown. Further work should be carried out in order to elucidate and characterize the structure of putative agent(s) present in MEBS and their effect on inhibition of mitochondrial-mediated apoptosis. This could be relevant in the management and treatment of diseases where there is need for downregulation of apoptosis.

\section{Funding}

This research did not receive any specific grant from funding agencies in the public, commercial, or not-for-profit sectors.

\section{References}

1. Arulmozhi DK, Veeranjaneyulu A, Bodhankar SL (2004) Neonatal streptozotocin-induced rat model of type 2 diabetes mellitus: a glance. Indian J Pharmacol 36(4): 217-221.

2. Van Belle TL, Coppieters KT, von Herrath MG (2010) Type 1 diabetes: etiology, immunology, and therapeutic strategies. Physiol Rev 91(1): 79118.

3. Kroemer G, Zamzami N, Susin SA (1997) "Mitochondrial control of apoptosis." Immunol Today 18(1): 44-51.

4. Tait SW, Green DR (2010) Mitochondria and cell death: Outer membrane permeabilization and beyond. Nat Rev Mol Cell Biol 11(9): 621-632.

5. Zou H, Li Y, Liu X, Wang X (1999) An APAF-1.cytochrome c multimeric complex is a functional apoptosome that activates procaspase-9. J Biol Chem 274(17): 11549-11556.

6. Halestrap AP, McStay GP, Clarke SJ (2002) The permeability transition pore complex: Another view. Biochimie 84(2-3): 153-166.

7. Martins KR (2006) Targeting apoptosis with dietary bioactive agents. Minireview 231(2): 117-130.

8. Lowel BB, Shulman GI (2005) Mitochondrial dysfunction and type 2 diabetes. Sciences 307(5708): 384-387.

9. Rolo AP, Palmeira CM (2006) Diabetes and mitochondrial function: Role of hyperglycaemia and oxidative stress. Toxicology and Applied Pharmacology 212(2): 167-178.

10. Adrienne LK, Telisha MS, Dale AD, Mathieu JL, Shannon MB (2010) Chronic ethanol consumption enhances sensitivity to $\mathrm{Ca}^{2+}$-mediated opening of the mitochondrial permeability transition pore and increases Cyclophilin D in liver. Am J Physiol Gastrointest Liver Physiol 299(4): G954-G966.

11. Stavrovskaya IG, Kristal BS (2005) The powerhouse takes control of the cell: Is the mitochondrial permeability transition a viable therapeutic target against neuronal dysfunction and death?. Free Radical Biology and Medicine 38(6): 687-697

12. Tascilar M, de Jong FA, Veinweij J, Mathijssen RH (2006) Complementary and alternative medicine during cancer treatment: beyond innocence. Oncologist 11(7): 732-741.

13. Johnson D, Lardy H (1967) Isolation of liver or kidney mitochondria. Methods Enzymol 10: 1094-1096.

14. Olorunsogo 00, Bababunmi EA, Bassir O (1979) Uncoupling effect of N - phosphonomethyl glycine on rat liver mitochondria. Biochem Pharm 28(6): 925-927.

15. Lapidus RG, Sokolove PM (1992) Inhibition by spermine of the inner membrane permeability transition of isolated heart mitochondria. FEBS Lett 313(3): 314-318.

16. Lowry OH, Rosebrough NJ, Farr AI, Randall RJ (1951) Protein measurements with the folin-phenol reagent. J Biol Chem 193(1): 260265.

17. Olorunsogo 00, Malomo SO (1985) Sensitivity of Oligomycin-inhibited respiration of isolated rat liver mitochondriato perfluidone, a fluorinated arylalkylsulfonamide. Toxicology 35(3): 231-240.

18. Bassir 0 (1963) Handbook of practical biochemistry. Ibadan University Press, Ibadan, Nigeria.

19. Varshney R, Kale RK (1999) Effect of calmodulin antagonists on radiation-induced lipid peroxidation in microsomes. Int Radiat Biol 58(5): 773-743.

20. Appaix F, Minatchy M, Riva Lavieille C, Olivaires J, Antonnson B, et al. (2000) Rapid spectrophotometric method for quantitation of cyctochrome c release from isolated mitochondria or permealized cells revisited. Biochimica et Biophysica Acta 1457(3): 175-181.

21. Allen L, Dockrell DH, Pattery T, Lee DG, Cornelis P, et al. (2005) Pyocyanin production by Pseudomonas aeruginosa induces neutrophil apoptosis and impairs neutrophil-mediated host defenses in vivo. J Immunol 174(6): 3643-3649. 


\section{ISSN: 2574-1241}

DOI: 10.26717/BJSTR.2019.19.003242

AO Olowofolahan. Biomed J Sci \& Tech Res

(c) (i) This work is licensed under Creative

Submission Link: https://biomedres.us/submit-manuscript.php

$\begin{array}{ll}\text { BIOMEDICAL } & \text { Assets of Publishing with us } \\ \text { RESEARCHES } & \text { - Global archiving of articles } \\ \text { - Immediate, unrestricted online access } \\ \text { - Rigorous Peer Review Process }\end{array}$

